AC 2012-3991: CREATING PARTNERSHIPS BETWEEN YOUR UNIVERSITY AND COMMUNITY-BASED OUT-OF-SCHOOL TIME PROGRAMS TO IMPROVE THE STEM PIPELINE

Dr. Barbara A. Christie, Loyola Marymount University

Barbara A. Christie is the Founding Director of the Science and Engineering Community Outreach program at Loyola Marymount University. 


\title{
Creating Partnerships Between Your University and Community-Based Out-of School Time Programs to Improve the STEM Pipeline
}

\begin{abstract}
In 2001, after receiving seed money from the Honda Foundation, Loyola Marymount University's College of Science and Engineering developed a community outreach program with the goal of increasing the pipeline of girls and underrepresented minorities studying science, technology, engineering, and mathematics (STEM) at the college level. To accomplish this goal, we started the Science and Engineering Community Outreach Program (SECOP). SECOP is a two-week residential pre-college summer school program with a focus on science and engineering. Engineering and mathematics faculty provide a similar curriculum taught in Engineering 101 and Pre-calculus College courses. The afternoon classes are project-oriented. Students design mousetrap cars using SolidWorks, and build their cars in the Mechanical Engineering Laboratory. The high school students purchase supplies for the mousetrap car from Home Depot and must keep their budget to $\$ 10$. At night, students work on group projects that include designing and building robots using LEGO Mindstorms NXT.
\end{abstract}

To recruit students, we created a partnership between our College and five communitybased out-of-school time programs in Southern California. By working with community organizations, we have reached highly motivated students who have a strong aptitude for science and mathematics. Over the past 11 years, 233 students from 73 different high schools in the Greater Los Angeles Area have participated in SECOP. We have received over $\$ 500.000$ in funding from foundations and engineering-based corporations. The demographics of the high school students include 140 females (60\%), and 93\% African American, Hispanic or Native American. The outcomes for the students who participated in SECOP have been outstanding. We have collected data on the alumni who have graduated high school and 4-6 years after they have graduated college. We contacted the alumni by phone and searching for them on facebook.

Of the students who attended SECOP and now have graduated from high school, 99\% have or are attending college. Sixty-six percent have select STEM majors in college and $39 \%$ selected engineering in particular. On a recent search of the alumni from 2001-2005 with an $80 \%$ return rate, we found that $97 \%$ have graduated from college and $29 \%$ have gone onto graduate or professional school including 3 in medical school, 1 in dental school, 1 in law school, 4 working on PhDs and 13 working toward masters or having completed masters degrees. Seventeen $(22 \%)$ of the college graduates are working as professional engineers, architects or computer scientists. This article discusses the methods used to develop a very valuable and meaningful community outreach program that continues to achieve its goal of helping improve the pipeline of students deciding to study STEM in college and going onto STEM careers. 


\section{Introduction}

Generation Y, Millennial Generation, or Generation Next are terms used to describe the demographic cohort born in the early 1990s. Although their titles of Generation Y or Generation Next mean they are following Generation X, this group of students currently in high school, have their own unique style and identity and are not to be underestimated or underrated. As the director of a community outreach program for the past eleven years, nothing has been more fulfilling than to observe the incredible strength of the young students of Generation Y.

The Science and Engineering Community Outreach Program (SECOP) is a two-week residential summer school program for students entering their sophomore or junior year in high school who have a strong aptitude and desire to study science, engineering or mathematics. SECOP is a collaborative partnership between our university and different academic enrichment programs in Southern California including: Young Black Scholars, College Bound, Boyle Heights College Institute, American Indian Clubhouse, and MOSTE (Motivating Our Students Through Experiences). Since 2001, two hundred and thirty-three students from 73 high schools in the Greater Los Angeles Area have participated in SECOP. By working with community organizations we have reached highly motivated students who are close to our university geographically. These community organizations are valuable sources of inspired students who have supportive families who are very eager to have their children participate in a summer program for two weeks.

SECOP focuses on introducing students to science, technology, engineering, and mathematics (STEM) careers and improving students' content knowledge in these topic areas. The goal of SECOP is to address the shortage of African American, Latino and Native American and female students studying STEM at college level by introducing students to pre-engineering and advanced mathematics classes early in their academic careers. The objectives of SECOP coincide with the objectives of American Society for Engineering Education (ASEE):

- increasing awareness of opportunities available in science, engineering and technical fields;

- increasing students' confidence to grasp mathematics, technology and science subjects;

- improving student achievement in mathematics, technology and science;

- mentoring students through the process of applying to college; and

- $\quad$ increasing the pipeline of underrepresented minorities in STEM majors.

The American Association for the Advancement of Science discusses the benefits of summer school programs for minority students and women in their study, "Investing in Human Potential: Science and Engineering at the Crossroads." The study recommends, "providing residential campus experiences such as overnights, summer programs, and bridge programs" (p.3) to help expand the base of participation in science, engineering and mathematics. None of the academic intervention programs listed above offer 
summer school classes to their participants. So our university is stepping up to fill a very important gap in the students' overall education in high school in general and their science and mathematics core in particular. During SECOP, students cover a curriculum which includes in pre-engineering, computer graphics, physics, mathematics, and SAT Preparation.

\section{Addressing the Need to Improve the Pipeline}

Historically, America's racial and ethnic minorities have been underrepresented in higher education in the science and engineering fields. Technology-based industries such as biomedical engineering, aerospace and computers are the nation's fastest growing and make up one-sixth of the total United States economy (Barret, 1997). Today, the United States is the world leader in the global Science, Technology, Engineering and Mathematics (STEM) enterprise. While national engineering baccalaureate production grew in 2010 by 5.3\% 78,347, the fractions of this total awarded to African Americans, Latinos, and American Indians, increased only slightly. Degrees earned by these three historically underrepresented group's peaked-in percentage terms-in 2003 at $11.6 \%$, then declined for several years and now, in 2010 , are back up to $11.5 \%$. These same race/ethnic groups are projected to make up $33.9 \%$ of the U.S. population graduating from high school in 2014. Engineering degrees awarded to women have followed a similar trajectory-growth through the 1990's with a percentage peak in 2000 at $20.6 \%$ of the total. In 2009, women represented $18 \%$ of the baccalaureates awarded in engineering (Society of Women Engineers).

Our university is seeking to help underrepresented students overcome the barriers they encounter while trying to enter into science, engineering and technology fields by improving academic preparation and expanding students' knowledge of the myriad of opportunities available for science and engineering majors. The University has the resources and intent to help students clear these obstacles by providing supplemental education with experienced teachers, state-of-the-art classroom facilities and supportive college students who act as counselors and mentors. Additional attention in advanced math and science courses such as calculus and physics before students enter college is an effective means of ensuring preparedness for science and engineering degrees.

"SECOP has given me the opportunity to experience science and engineering on a first hand basis. I think it is a very challenging and rewarding career, and I feel that it is something I'd want to do." Female Student from Sacred Heart High School in Boyle Heights

\section{Benefits to Working with Community Organizations}

For the typical engineering department working with local high schools to improve the pipeline of females and minorities entering engineering and other technical fields can prove to be very challenging. Most colleges do not have the infrastructure to support extra phone calls or a community outreach partnerships. Immediately many questions come to mind when trying to develop a program: Who do we speak with at the high 
school: the principal, counselors, or individual teachers? How do we recruit for students? Do we visit during science and mathematics classes, or have a school assembly or invite parents for a career night discussion? Many times you will have to call a teacher at home in the evenings or on their cell phone to discuss a project or program. The engineering faculty and staff within a university are already stretched between research and teaching and do not have the luxury of time for community outreach programs unless they can operate smoothly and efficiently. The barriers to working with several high schools in your community can be overwhelmingly complex and create a sense of frustration that will prevent an outreach project from ever getting off the ground.

One solution to improving your odds of reaching high achieving low-income students who have a strong aptitude for science and mathematics is to work directly with community organizations that provide academic enrichment specifically to minority students or to young girls such as MOSTE in Los Angeles. Many communities around the United States have church or high school outreach organizations that work with minority students or girls on Saturdays or after school during the academic school year. These organizations are valuable sources of inspired students who are tailor-made for recruitment into a science, engineering or mathematics department.

The benefits of working directly with community organizations include: saving time, consistency of access, inspired students, and dedicated families. All of the academic enrichment programs I have worked with over the past nine years have staff members that answer the phones. The organizations are easily accessible to anyone in an engineering department because they can be located in the phone book or on the web. One is able to work directly with the organization's president or the educational director in a timely fashion. I find working with community organizations much easier than trying to work with individual high schools.

Academic enrichment programs are very interested in creating a partnership with a university to help encourage and inspire their students. They want to use the partnership to help advertise their program to perspective families. The partnership creates a win-win situation. The partnership can develop rapidly and run smoothly over many years.

Families that drive their children to Saturday Programs are very motivated to help their child receive as many advantages as possible by utilizing resources in their communities. A family's motivation, improving their child's chances of being accepted into college and receiving scholarships, is often the compelling force that drives parents to be a taxi driver on Saturday mornings. A university that is willing to provide focused enrichment in topic areas not traditionally discussed in the high school curriculum such as engineering or computer science will be doing a service and recruiting students.

\section{About the Science and Engineering Community Outreach Program}

Engineering corporations heavily subsidize the Program. The students' families only pay a minimal fee to participate at the time of registration. Four faculty members teach 
courses in pre-engineering, mathematics, mechanical engineering, computer graphics (SolidWorks), and manufacturing engineering. During the afternoon courses students work on two different projects: designing a mouse trap car on the computer using SolidWorks and then building the car in the Mechanical Engineering Lab and designing an object on SolidWorks and then creating their design using a FDM 1650 rapid prototyping machine. The students receive lectures from two mechanical engineering professors on the engineering concepts behind each project.

Five minority students studying science and engineering act as counselors during the Program. Their roles include being teachers' aids during classes, project leaders for each of the group projects, and resident assistants in the dormitories.

Parents visit SECOP on two occasions for Family Night Events. The events include dinner and discussions on important topics including financial aid and scholarships for college and future jobs in science, technology and engineering. Guest speakers from Jet Propulsion Laboratory, NASA, Boeing, Southland Industries and the Metropolitan Water District of Southern California discuss engineering with the students on Career Day. Different science and engineering-based field trips to the Petersen Automotive Museum, Disney's Imagineering, Ballona Wetlands and Northrop Grumman give students a firsthand look at the day-to-day work of engineers and scientists.

Students are housed on campus in Rains Dormitory and eat their meals in the Lair Dining Hall. In the evening and on weekends students utilize the Fritz Burns Recreation Center for basketball, working out, tennis and swimming.

The summer school program has four components that enable young scholars (and their families) to visualize themselves as college students studying mathematics, science or engineering.

\section{Academic Preparation for Engineering and Science Degrees Component}

The results of the Third International Mathematics and Science Study (TIMSS) show that, as a nation, we are not adequately preparing our high school students for college science and math courses. High school seniors in the United States placed $28^{\text {th }}$ in mathematics and $17^{\text {th }}$ in science. During the SECOP, there is a strong focus on providing the students with an in-depth learning experiences and teaching them topics not traditionally taught in high school. Students work together in a team with the support of engineering and science student mentors to design and produce a project. During the summer of 2009, each student was assigned to a group project and had to design and build a robot using LEGOS MINDSTORMS NXT Kits. The students present their projects the last day of the program. They share their results with the other students. Additional benefits of the group projects included improving team working skills and public speaking ability. 


\section{Career Component}

The program manager, Dr. Barbara Christie, plans a Career Day during SECOP. The guest speakers work for engineering -based organizations and all are African American and Latino leaders in mechanical, civil and electrical engineering fields. Several field trips to different science and engineering-based companies exposed students to different career opportunities. In the past several years the field trips have included visiting Disney’s Imagineering, Northrop Grumman Space Park, and Ballona Wetlands.

"SECOP has definitely influenced my feelings on studying engineering. At one point in time I did not really know what engineering was. Now I feel a lot more aware of what engineering is all about." Male Student King Drew H.S.

\section{Family Component}

The support and understanding of parents is very important to first-generation college students. Parents need help with information on different ways to foster math and science interests and persistence in their children. Once a week we invite the family members of participants to attend a College Life seminar and dinner. Each week we focus on a different aspect of college life. Week 1: "How to Prepare for College Financially", (families will be given a list of foundations that offer scholarships such as the American Chemical Society or American Society of Mechanical Engineers). Week 2: "Benefits of College and the Success Rates of College Graduates in Science, Engineering and Technology Careers".

"I'm so pleased my daughter had the opportunity to participate in the SECOP program. She needed the first hand experience to gain an understanding of the types of issues/problems she'll be asked to solve as an engineering student/engineer. She really enjoyed the friendships she made and worked very hard to tackle the assignments. You are providing an invaluable service for both LMU and the underserved segments of the community." Mother of SECOP participant

\section{College Life Component}

First-generation college students often do not have examples of what college life is and are more likely to be intimidated by a college or university campus and lifestyle than students from families who are second or third generation college graduates. Attending SECOP provides students insight into the college experience. Students have the benefit of computer equipment and other technology that their high schools cannot provide. Sleeping in the dorms and eating in the cafeteria helps students anticipate what their lives will be like in a few short years once they complete high school. 


\section{Results from Eleven Years of SECOP}

As part of the program we provide students with a pre-questionnaire and postquestionnaire regarding their cognitive and affective domains regarding STEM Fields. We request the students to answer questions including: What is engineering?, list three jobs a mechanical engineer would perform, and after completing the SECOP summer program do you feel you may decide to study engineering or a similar field when you go to college? These questions have had very interesting results over 11 years. When the program first began in 2001, most of our students stated in their pre-questionnaires that they were not interested in engineering and could not answer any questions regarding engineering. They wanted to study science and had a much stronger understanding of this field. Our results in the post-questionnaire showed that we had a strong influence on providing a foundation toward helping students learn more about the field and developing a desire to study engineering in their future. Yet, over the years we have seen a far greater number come into our program wanting to be engineers and leaving with an even greater sense that they are choosing the correct major. Most post-questionnaire responses stated that the program has helped "encourage them to follow engineering".

"I knew I liked math and science, but I didn't know what I wanted to study in college or do for a career. SECOP really opened my eyes to engineering, and showed me what college would be all about." Female Student (SECOP 2001) from Chino High School who is currently working as a professional civil engineer.

"SECOP helped me become more mature and independent when preparing for college. The program also gave us an incredible opportunity to explore the expanding field of engineering" Female Student (SECOP 2006) currently studying environmental health science at Tulane University.

\section{Science and Engineering Community Outreach Program Statistics 2001-2010}

Since 2001, 233 high school students have participated in the Science and Engineering Community Outreach Program (SECOP) from 73 different high schools in the Greater Los Angeles Area. The goal of SECOP is to improve the pipeline of underrepresented minorities studying Science, Technology, Engineering and Mathematics (STEM) at college level.

Dr. Barbara Christie has contacted 165 individuals out of 206 participants from ten summers (SECOP 2001-2010) who have graduated high school (80\% response rate). Ninety- five percent of the students contacted are classified as underrepresented in science and engineering (African American, Latino, Native American or female).

During the study Dr. Christie found 164 (99.4\%) individuals have stated they are attending college or have graduated from college, and 1 student has joined the United States Air Force. Of the 164 students attending college, 154 have selected to attend 4year institutions (94\%) directly after high school. The SECOP Alumni have selected 76 
different colleges and universities across the United States. The largest feeder institutions include Loyola Marymount University (15), University of California, Riverside (10), UCLA (8), and Rensselaer Polytechnic Institute (7). The results of the selected majors are below:

\author{
111/164 Science, Technology, Engineering or Mathematics (STEM Degrees) \\ $67 \%$ \\ 40/164 Science \\ $24 \%$ \\ 67/164 Engineering \\ $41 \%$ \\ 04/164 Mathematics \\ $02 \%$ \\ 59/91 Females in STEM degrees (91 of the 164 respondent were female) \\ $65 \%$ \\ 28/59 Females Science \\ $47.5 \%$ \\ 28/59 Female Engineering \\ $47.5 \%$ \\ 03/59 Female Mathematics \\ $5 \%$ \\ 28/91 Female Science \\ $31 \%$ \\ 28/91 Female Engineering \\ $31 \%$ \\ 03/91 Female Mathematics \\ $3 \%$
}

\title{
Data on SECOP 2001-2005 Participants College Graduation Rates
}

Between 2001-2005, SECOP enrolled 100 participants. Based on research done in February 2012, Dr. Christie found the following results:

Of an original group of 100 participants of SECOP cohorts from 2001-2005, Dr. Christie was able to contact 84 participants upon their high school graduation. The original results showed that $99 \%$ of these students entered college and $1 \%$ joined the United States Air Force. Of the 83 students who attended college, 81 selected 4-year institutions (96.4\%) directly out of high school. Fifty-six students (67\%) chose Science, Technology, Engineering or Mathematics (STEM) Degrees. The breakdown upon college entrance was 14 science majors, 38 engineering majors and 4 mathematics majors.

Of the original study group of 83 students, Dr. Christie has been able to contact, through a recent study, 79 individuals. Of these 79 individuals, $97 \%$ have graduated from university (two participant are still in college). According to the U.S. Department of Education, the six-year graduation rate of Latino and African American students is $42 \%$ and $49 \%$ respectively. SECOP is proud that its graduation rate (4-5 year rate) is twice the national average.

From this study group, SECOP has had 43 participants graduate in STEM fields out of 56 
who initially selected a STEM major, this is a $77 \%$ retention rate. The overall graduation rate for the 43 participants who selected STEM degrees is 56\% (43 out of 77). The Commission on Professionals in Science and Technology reports that underrepresented minorities made up 16.5\% of bachelor's degrees received in STEM fields in 2004. Therefore, the results of this study shows that SECOP Alumni graduating with STEM Degrees is 3.5 times the national average.

For engineering degrees in particular the results were very similar. Since 24 out of the 77 participants graduated as engineers, then the graduation rate is $31 \%$. According to the National Action Council for Minorities in Engineering (NACME), the national average for the same demographic group is $11.5 \%$. In conclusion, SECOP results indicate a graduation rate in engineering degrees that is 2.5 times the national average.

\section{Post Graduate Work of SECOP 2001-2005 Cohorts}

22 of $77(29 \%)$ of the SECOP Alumni are attending or have attended graduate school or professional school after graduating with a BS Degree:

3 are in Medical Schools (UCLA, University of Utah, Michigan State)

1 is in Dental School (UCLA)

1 is in Law School (Loyola Law School)

4 are studying for PhDs (Mathematics/USC, Biomedical Eng./UCR, Anthropology/UCR, Physics/Stanford University)

13 are working toward or have received MA or MS degrees.

\section{Conclusion}

There are many challenges to overcome while designing and implementing a community outreach program. Finding funding is the largest of these challenges but if you can develop private-public partnerships with local corporations, it has been my experience that they consistently fund a program once they adopt it and develop a bond with the university. Another challenge is keeping point people engaged with the program. There can be a high level of turn over of staff in community-based programs, so often you must keep introducing your program to a new point person in an organization.

SECOP has accomplished many of its objectives over the past nine years. Improving mathematics scores was measured through pre and post testing. The scores of the mathematics pre and post-tests showed that $65 \%$ of the students increased their scores by $10 \%$ or more. The other $35 \%$ of the participants were within $10 \%$ of their original pretest scores. These scores are encouraging and indicate that SECOP helped improve the participants' mathematics achievement. 
The following are four of the responses from the student evaluation $(\mathrm{N}=210)$ : (1 strongly disagree, 2 disagree, 3 average, 4 agree, 5 strongly agree)

\begin{tabular}{llllll} 
& 1 & 2 & 3 & 4 & 5 \\
\hline The instructors improved my understanding of what & $0 \%$ & $0 \%$ & $7 \%$ & $32 \%$ & $61 \%$
\end{tabular} engineers do.

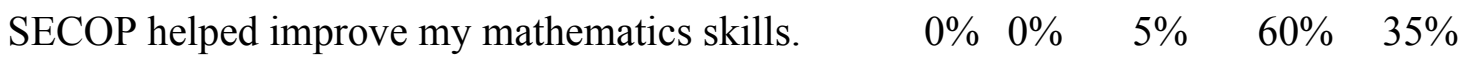

I would recommend this Program to a friend. $\quad \begin{array}{llll}0 \% & 0 \% & 1 \% & 20 \%\end{array}$

The computer class helped improve my understanding $\quad 0 \% \quad 0 \% \quad 14 \% \quad 30 \% \quad 56 \%$ of computers and their capabilities.

The next step for the program is to work in an Urban Ecology Section to our curriculum. We have just started a Center for Urban Resilience (CUR) and feel it is very important that the young people of Los Angeles recognize the importance of a sustainable city. They can go back to their neighborhoods after participating in our program and be Citizen Scientists. We want them to be very active in their communities to fight for safer streets, more green space, community gardens, less water runoff to the ocean and better transportation. The future success of Southern California relies on a well-prepared and highly trained population. Young students from Generation Y must be part of the engineering landscape transformation that will take place over the next 50 years. Achieving the goal of improving the participation of underrepresented students in STEM degrees and careers is important to the financial success of the United States in a more and more globally competitive world and the writer hopes that this paper gives some insight into how to design and implement an outreach program at your institution.

\section{References}

Bailey, S. (1992). Shortchanging girls, shortchanging America: A call to action. Washington, DC: Women's Educational Foundation, American Association of University Women.

Hsiao, Karin Peterson (Nov. 1992). First-generation college students. ERIC Digest. ED351079

Matyas, M. L. \& Malcom, S.(1992). Investing in human potential: Science and engineering at the crossroads. American Association for the Advancement of Science. Washington, DC. 